\title{
Characteristics and surgical outcomes of symptomatic patients with hypertrophic cardiomyopathy with abnormal papillary muscle morphology undergoing papillary muscle reorientation
}

\author{
Deborah H. Kwon, MD, ${ }^{\mathrm{a}}$ Nicholas G. Smedira, MD, ${ }^{\mathrm{b}}$ Maran Thamilarasan, MD, ${ }^{\mathrm{a}}$ Bruce W. Lytle, MD, \\ Harry Lever, MD, and Milind Y. Desai, MD ${ }^{\mathrm{a}}$
}

\begin{abstract}
Objective: In patients with hypertrophic cardiomyopathy with bifid hypermobile papillary muscles and a dynamic left ventricular outflow tract gradient, we performed surgical papillary muscle reorientation, fixing the mobile papillary muscle to the posterior left ventricle to reduce mobility. We report the outcomes of patients with hypertrophic cardiomyopathy undergoing surgical papillary muscle reorientation versus those of patients undergoing standard surgical procedures.
\end{abstract}

\begin{abstract}
Methods: We studied 204 consecutive patients with hypertrophic cardiomyopathy undergoing surgical intervention (after consensus decision) for symptomatic left ventricular outflow tract gradient. Preoperative and postoperative maximal (resting/provocable) left ventricular outflow tract gradients were recorded by using echocardiographic analysis.
Results: The population was divided into 3 groups: (1) isolated myectomy ( $\mathrm{n}=143$; age, $54 \pm 14$ years; $48 \%$ men), (2) myectomy plus mitral valve repair/replacement ( $\mathrm{n}=39$; age, $54 \pm 13$ years; $54 \%$ men), and (3) pap- illary muscle reorientation with or without myectomy $(\mathrm{n}=22$; age, $50 \pm 14$ years; $59 \%$ men). The mean pre- operative $(103 \pm 32,103 \pm 32$, and $114 \pm 36 \mathrm{~mm} \mathrm{Hg} ; P=.3)$ and predischarge $(15 \pm 18,14 \pm 14$, and 16 $\pm 21 \mathrm{~mm} \mathrm{Hg} ; P=.9$ ) maximal left ventricular outflow tract gradients were similar. There were no deaths either in the hospital or at 30 days. At a median follow-up of 166 days (interquartile range, 74-343 days), 21 of 22 patients in group 3 were asymptomatic. One patient in group 3 had a symptomatic left ventricular outflow tract gradient $(87 \mathrm{~mm} \mathrm{Hg})$ requiring mitral valve replacement.

Conclusions: In patients with hypertrophic cardiomyopathy with bifid hypermobile papillary muscles (even with a basal septal thickness $<1.5 \mathrm{~cm}$ ), papillary muscle reorientation reduces the symptomatic left ventricular outflow tract gradient. Long-term outcomes need to be ascertained. (J Thorac Cardiovasc Surg 2010;140:317-24)

Video clip is available online.

Hypertrophic cardiomyopathy (HCM) is a complex disorder with a broad phenotypic expression and varied clinical outcomes. The most common morphologic form involves basal interventricular septal hypertrophy and concomitant systolic anterior motion (SAM) of the anterior mitral valve leaflet, resulting in dynamic left ventricular outflow tract (LVOT) obstruction (Figure 1, A). ${ }^{1,2}$ The degree of dynamic LVOT

\footnotetext{
From the Tomsich Department of Cardiovascular Medicine ${ }^{a}$ and Department of Cardiothoracic Surgery, ${ }^{\mathrm{b}}$ Heart and Vascular Institute, Cleveland Clinic, Cleveland, Ohio.

Disclosures: None.

Received for publication May 14, 2009; revisions received Aug 3, 2009; accepted for publication Oct 25, 2009; available ahead of print Dec 28, 2009.

Address for reprints: Milind Y. Desai, MD, Tomsich Department of Cardiovascular Medicine, Heart and Vascular Institute, Cleveland Clinic, 9500 Euclid Av, Cleveland, OH 44195 (E-mail: desaim2@ccf.org).

$0022-5223 / \$ 36.00$

Copyright (c) 2010 by The American Association for Thoracic Surgery

doi:10.1016/j.jtcvs.2009.10.045
}

obstruction has prognostic significance. ${ }^{3}$ Therefore surgical and percutaneous treatments have traditionally focused on surgically removing or percutaneously ablating (with alcohol) part of the basal interventricular septum, with excellent long-term outcomes. ${ }^{4-8}$ However, multiple previous studies have cited other concomitant contributors to dynamic LVOT obstruction, particularly mitral leaflet and subvalvar pathology (Figure 1, $B$ and $C$ ).$^{9-12}$ As a result, surgical techniques that combine extensive myectomy with or without mitral valve surgery have evolved over time, with excellent outcomes. ${ }^{13}$ However, dynamic LVOT obstruction is increasingly recognized in patients with HCM with minimal or no basal septal hypertrophy (Figure 1,D) ${ }^{14,15}$ In some patients with LVOT obstruction, abnormal papillary muscle morphology, including anteroapical displacement and bifid papillary muscles, has been frequently observed. ${ }^{10,16}$ In a recent study we demonstrated that abnormal papillary muscle morphology was associated with dynamic LVOT obstruction, independent of basal septal thickness. ${ }^{10} \mathrm{We}$ have noticed that a subset of patients with dynamic LVOT obstruction have bifid and hypermobile papillary muscles, such that they potentially added to the obstructive physiology, even without significant basal septal hypertrophy. To optimally reduce/abolish dynamic 


\section{Abbreviations and Acronyms \\ $\mathrm{CMR}=$ cardiac magnetic resonance \\ $\mathrm{HCM}=$ hypertrophic cardiomyopathy \\ LVOT $=$ left ventricular outflow tract \\ SAM $=$ systolic anterior motion}

LVOT obstruction in such patients, we have adapted a surgical approach to reorient the papillary muscles away from the LVOT (with or without myectomy). ${ }^{15,17} \mathrm{We}$ report the baseline characteristics and short-term outcomes of patients with HCM who underwent papillary muscle reorientation while comparing them with patients who underwent standard surgical approaches (myectomy with or without mitral valve surgery) for relief of dynamic LVOT obstruction.

\section{MATERIALS AND METHODS}

Between January 2007 and July 2008, 237 patients with HCM were referred for surgical intervention for LVOT obstruction after undergoing a comprehensive clinical, electrocardiographic, and multimodality imaging evaluation. All patients were referred for surgical intervention only after consensus between cardiologists and cardiothoracic surgeons experienced in the management of HCM. HCM was defined as a hypertrophied and nondilated left ventricle in the absence of another cardiac or systemic disease that could result in a similar magnitude of hypertrophy. ${ }^{1,2}$ Of these 237 patients, 33 also had concomitant significant aortic valve disease, subaortic membrane, or both, necessitating complex procedures in addition to myectomy (including aortic valve replacement, membrane resection, or both). These patients were excluded from the current analysis. Hence the final study population consisted of 204 patients who underwent surgical intervention for symptomatic, dynamic LVOT obstruction. All patients had intractable symptoms despite taking medications at maximum tolerable dosages. Baseline demographic, clinical, and medication data, along with postoperative clinical data, were obtained from an institutional database (an ongoing institutional review board-approved registry). In addition, for the group of patients who underwent papillary muscle reorientation (group 3 , as described below), assessment of symptoms in the postoperative period was ascertained by means of a telephone call, outpatient clinic visit, or both. The Social Security Death Index was queried to determine survival for all patients. When possible, cause of death was ascertained.

\section{Imaging Protocol}

Baseline and postoperative (predischarge) surface echocardiograms were performed with commercially available instruments (HDI 5000; Philips Medical Systems, N.A., Bothell, Wash and Acuson Sequoia; Siemens Medical Solution USA, Inc, Malvern, Pa) as part of standard clinical practice. Basal interventricular septal thickness was recorded according to American Society of Echocardiography recommendations. ${ }^{18}$ Left ventricular outflow peak velocity was measured by means of continuous-wave Doppler echocardiography, and LVOT pressure gradient was estimated by using the simplified Bernoulli equation. ${ }^{19}$ Care was taken to avoid contamination of the LVOT waveform by the mitral regurgitation jet. ${ }^{3}$ In patients with resting LVOT gradients of less than $30 \mathrm{~mm} \mathrm{Hg}$, provocative maneuvers, including Valsalva and amyl nitrite, were used. In 160 patients with resting LVOT gradients of less than $100 \mathrm{~mm} \mathrm{Hg}$, exercise echocardiographic analysis was performed, as previously described. ${ }^{20}$ Maximal resting gradient was defined as the maximum (either resting, provoked, or after exercise) LVOT gradient in a given patient. The degree of resting mitral regur- gitation was assessed by means of color Doppler scanning. After incorporation of jet width, volume, flow convergence, ${ }^{21}$ and left atrial size, a composite grade of 0 to $4+(0$, none; 0.5 , trivial; $1+$, mild; $2+$, moderate; $3+$, moderately severe; and $4+$, severe) was assigned to each patient. Also, the direction of the mitral regurgitant jet was noted in each patient. A characteristic posteriorly directed mitral regurgitant jet with associated SAM was deemed to be due to dynamic LVOT obstruction. On the other hand, the patient was categorized as having intrinsic mitral valvular pathology if the leaflets were abnormally thickened, calcified, or elongated; had restricted mobility; and had a concomitant central or anteriorly directed jet.

All patients undergoing surgical intervention underwent intraoperative transesophageal echocardiographic analysis in a standard fashion. ${ }^{22}$ In addition, patients underwent standard postoperative surface echocardiographic analysis before discharge, as described above, including assessment of resting and provocable (Valsalva and amyl nitrite) maneuvers. Stress echocardiographic analysis was not performed postoperatively.

Also, 122 patients (without standard contraindications, including pacemaker, implantable cardioverter defibrillators, aneurysm clips, significant arrhythmias, or severe claustrophobia) underwent a comprehensive electrocardiographically gated cardiac magnetic resonance (CMR) examination on 1.5 T scanner (Siemens Avanto; Siemens Medical Solutions, Erlangen, Germany) to assess left ventricular morphology, as previously described. ${ }^{10}$

During echocardiographic and CMR examinations, special attention was given to papillary muscle morphology (including the number of heads, abnormal attachment to the anterior mitral leaflet, the presence of bifid muscles, and hypermobility of the muscle heads), along with their contribution to dynamic LVOT obstruction (see Videos 1 and 2). Papillary muscles were deemed hypermobile based on the presence of all of the following criteria: (1) excessive motion, (2) close proximity of the papillary muscle to the interventricular septum in late systole, and (3) the presence of concomitant SAM of the mitral valve. We recorded provocable SAM and LVOT obstruction, even in the absence of significant basal septal hypertrophy (Figure 2). Because there is no previously described objective method to define the hypermobility of papillary muscles, it was a consensus definition after discussion between the cardiologists and cardiothoracic surgeons.

\section{Surgical Technique}

The type of operation was decided based on expert consensus after thorough evaluation between cardiologists and cardiothoracic surgeons experienced in managing patients with HCM, taking into account the findings on preoperative imaging evaluation and intraoperative findings (HML, BWL, NGS, MT, and MYD). In our surgeons' experience of multiple hundreds of myectomies over the last more than 10 years, they have found the transaortic approach much easier compared with the transatrial approach. Hence all procedures were performed with the transaortic approach. Specific issues taken into consideration included basal septal thickness and mitral valve and papillary muscle morphology. The patients were divided into the following groups based on the surgical techniques used: (1) isolated myectomy $(\mathrm{n}=$ 143), (2) myectomy plus mitral valve repair/replacement $(\mathrm{n}=39)$, and (3) papillary muscle reorientation with or without myectomy $(n=22)$. The details of the first 2 techniques have been described previously. ${ }^{8,13}$

To perform surgical reorientation (group 3), papillary muscles had to be deemed bifid and hypermobile on multimodality imaging (including intraoperative transesophageal echocardiographic analysis), with the final decision made on intraoperative visualization by the surgeon. The papillary muscle realignment procedure was performed through the aortic valve. A pledgeted mattress suture was placed posterior to the most posterior papillary muscle head, avoiding entanglement with the chordae. It was then passed through the anterior head, avoiding twisting of the papillary muscle (Figure 3 and see Video 3 ). The sutures were passed through the fibrous portion to avoid ischemia of the papillary muscle. One or more mattress sutures were used to realign the papillary muscles, and both anterolateral and posteromedial papillary muscles have been realigned as deemed necessary. ${ }^{17}$ The degree to which the sutures were tightened was subjectively decided by the 


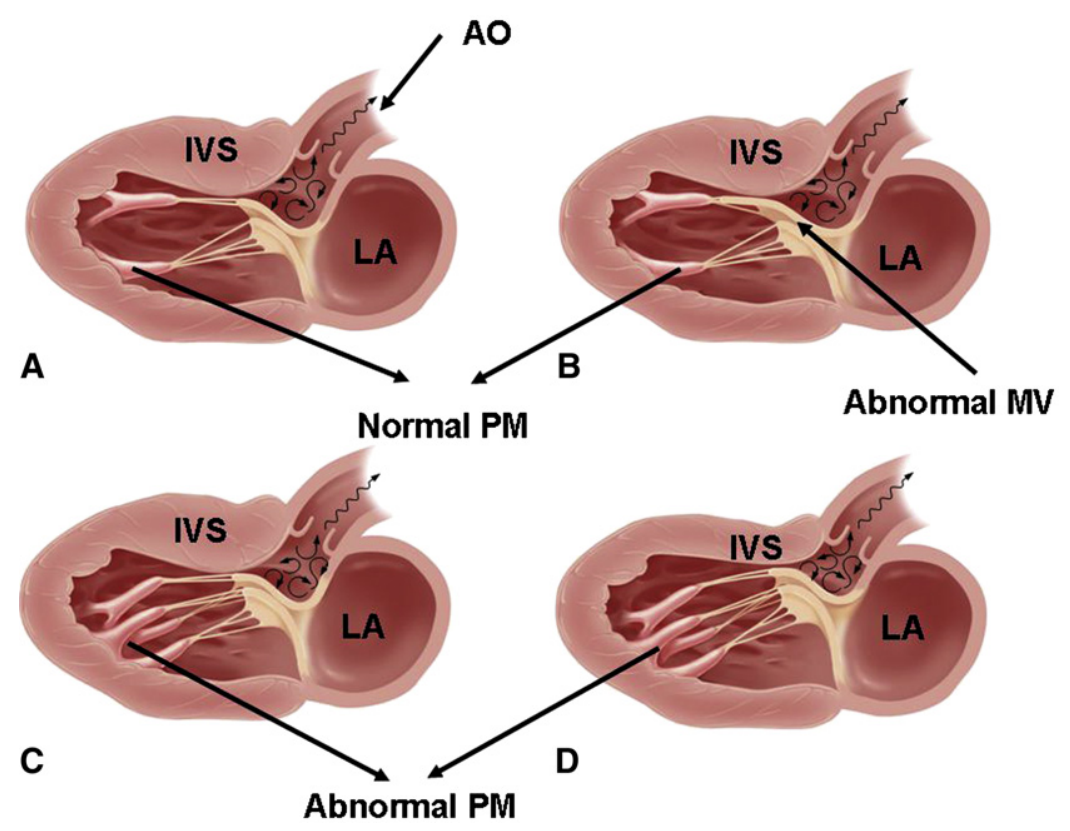

FIGURE 1. Schematic representation of different phenotypic presentations of dynamic left ventricular outflow tract obstruction in patients with hypertrophic cardiomyopathy. A, Typical basal septal hypertrophy resulting in systolic anterior motion of the mitral valve and outflow tract obstruction. B, Abnormal anterior leaflet of the mitral valve in addition to basal septal hypertrophy, resulting in systolic anterior motion of the mitral valve and outflow tract obstruction. C, Hypermobile bifid papillary muscles, along with basal septal hypertrophy, resulting in systolic anterior motion of the mitral valve and outflow tract obstruction. D, Hypermobile bifid papillary muscles without basal septal hypertrophy, resulting in systolic anterior motion of mitral valve and outflow tract obstruction. IVS, Interventricular septum; $A o$, aorta; $L A$, left atrium; $P M$, papillary muscles; $M V$, mitral valve.

surgeon in the operating room, such that it substantially reduced the hypermobility, hence relieving the LVOT obstruction, which was confirmed intraoperatively with an isoproterenol challenge.

\section{Statistical Analysis}

Baseline demographics, risk factors, and clinical variables are descriptively summarized for the group. Continuous variables are expressed as means \pm standard deviations or medians with interquartile ranges. Categorical data are presented as percentage frequencies. Differences between the

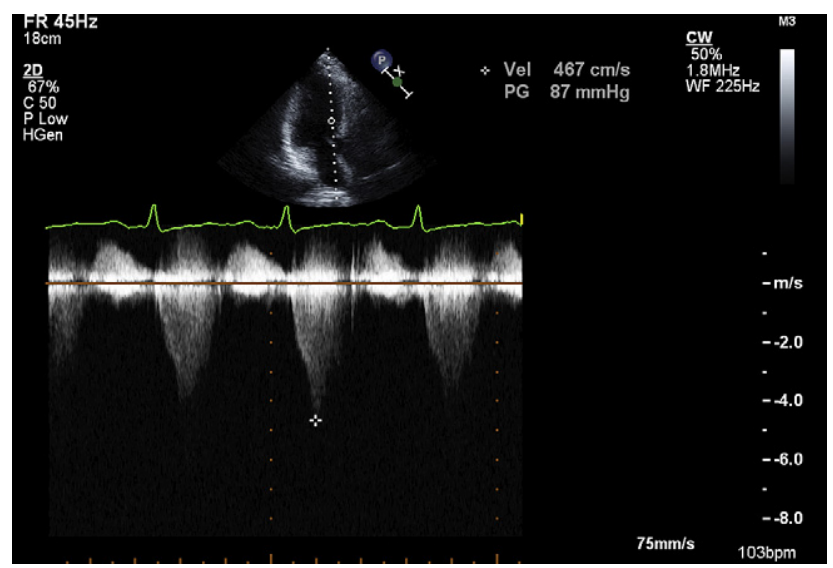

FIGURE 2. Apical long-axis view in the patient (as in Videos 1-3) without significant basal septal hypertrophy demonstrating the characteristic latepeaking Doppler profile across the left ventricular outflow tract, suggesting dynamic obstruction. groups were compared by using the Student's $t$ test or analysis of variance for continuous variables (Mann-Whitney test for nonparametric variables, where appropriate) and the $\chi^{2}$ test for categorical variables. Data assembly and basic statistical comparisons were performed with JMP Software version 6.0.2. Advanced statistical analysis was performed with Statistica version 6.1 (Statsoft, Tulsa, Okla).

\section{RESULTS}

Baseline clinical and demographic criteria for all the groups are shown in Table 1. There were no significant differences in age, sex, and standard clinical risk factors between the different groups. However, as might be expected, patients with concomitant mitral valvular pathology had increased severity of mitral regurgitation and frequency of atrial fibrillation. Thirteen patients in group 1 had advanced conduction disease at baseline (including 6 with right bundle branch block, 3 with bifascicular block, and 4 with left bundle branch block). No patients in the other groups had conduction disease at baseline.

\section{Baseline Echocardiographic Data}

Within the study population, all patients had a preoperative resting surface echocardiogram and an intraoperative transesophageal echocardiogram. Eighty-two patients in group 1, 25 in group 2, and 15 in group 3 had a preoperative CMR evaluation. The preoperative echocardiographic data are shown in Table 2. All patients had a preserved left 


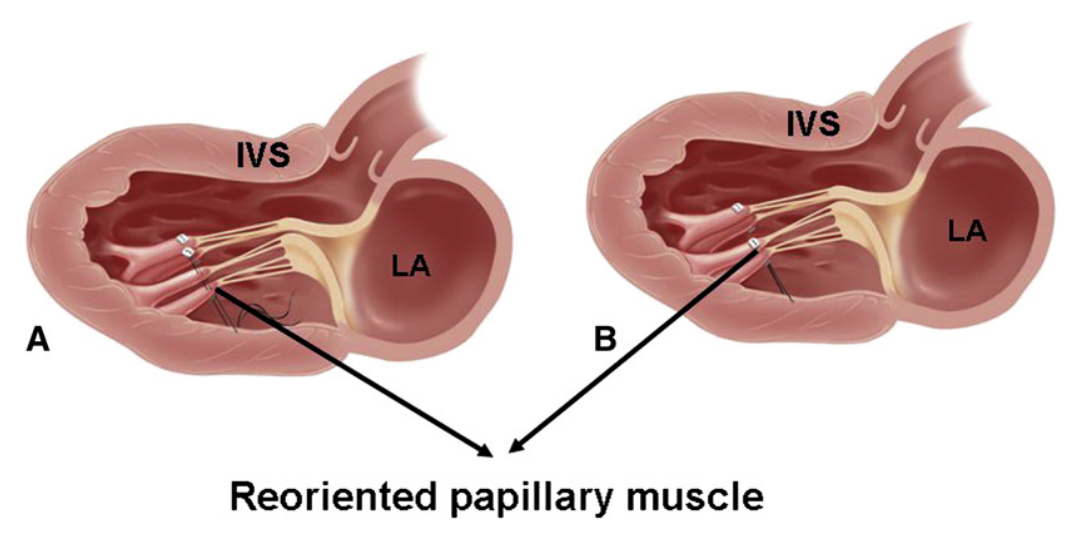

FIGURE 3. Schematic representation demonstrating reorientation of abnormal bifid papillary muscles away from the left ventricular outflow tract. In this demonstration both anterolateral and posteromedial papillary muscles are realigned, abolishing the outflow tract gradient. IVS, Interventricular septum; LA, left atrium.

ventricular ejection fraction, with no difference between groups. All patients had a maximal (either resting or provocable) LVOT gradient of greater than $50 \mathrm{~mm} \mathrm{Hg}$ on Doppler echocardiographic analysis. There was no significant difference in the maximal LVOT gradient between the groups. The mean basal septal thickness was similar in the first 2 groups; however, it was significantly lower in group 3. All patients in group 2 were deemed to have intrinsic mitral valve pathology in addition to SAM of the mitral valve. On multimodality imaging evaluation, all patients in group 3 had hypermobile and bifid papillary muscles, which were thought, by a consensus opinion of at least 2 authors, to aid in dynamic LVOT obstruction.

In group 3 there were 11 patients (mean age, $49 \pm 18$ years; $73 \%$ men) with a maximal basal septal thickness of less than $1.5 \mathrm{~cm}$. All these patients were symptomatic $(100 \%$ with New York Heart Association [NYHA] class $>$ II), and 10 of 11 were taking $\beta$-blockers. The maximal LVOT gradient was similar to those of the other groups $(124 \pm 36 \mathrm{~mm} \mathrm{Hg})$.

\section{Perioperative Data}

There were no intraoperative deaths in the study population. There was $0 \%$ in-hospital or 30 -day mortality. There was no difference between the treatment groups in terms of hospital admission days, intensive care unit length of stay, or postoperative complications. There was no difference in postsurgical LVOT gradients or degree of mitral regurgitation between the treatment groups. Also, of the 16 patients with new pacemaker-dependent complete heart block, 10 had pre-existing advanced conduction disease. None of the patients who underwent papillary muscle reorientation in group 3 had conduction abnormalities necessitating permanent pacemaker implantation. The clinical perioperative data, divided into different groups, is shown in Table 3.

\section{Follow-up Data}

As shown in Table 3, there were no intraoperative or inhospital deaths. During a median follow-up (for survival) of 311 days (interquartile range, 150-458 days), there

TABLE 1. Baseline clinical characteristics of the study population

\begin{tabular}{|c|c|c|c|c|}
\hline & $\begin{array}{l}\text { Group 1, myectomy } \\
\qquad(\mathrm{n}=143)\end{array}$ & $\begin{array}{l}\text { Group 2, myectomy }+ \text { MV surgery } \\
((n=39)\end{array}$ & $\begin{array}{c}\text { Group 3, PMR } \pm \text { myectomy } \\
(n=22)\end{array}$ & $\begin{array}{c}P \\
\text { value }\end{array}$ \\
\hline Age (y) & $54 \pm 14$ & $54 \pm 13$ & $50 \pm 14$ & .4 \\
\hline Male sex & $69(48 \%)$ & $21(54 \%)$ & $16(73 \%)$ & .09 \\
\hline Hypertension & $76(53 \%)$ & $24(62 \%)$ & $13(59 \%)$ & .6 \\
\hline Diabetes mellitus & $15(10 \%)$ & $8(21 \%)$ & $1(5 \%)$ & .1 \\
\hline Stroke & $3(2 \%)$ & $1(3 \%)$ & $1(5 \%)$ & .8 \\
\hline Smoking & $51(36 \%)$ & $14(36 \%)$ & $4(18 \%)$ & .8 \\
\hline Atrial fibrillation & $7(5 \%)$ & $7(18 \%)$ & $0(0 \%)$ & .009 \\
\hline Permanent pacemaker & $3(2 \%)$ & $6(15 \%)$ & $4(18 \%)$ & .8 \\
\hline Syncope & $35(24 \%)$ & $6(15 \%)$ & $4(18 \%)$ & .4 \\
\hline$\beta$-Blocker & $118(83 \%)$ & $31(79 \%)$ & $15(68 \%)$ & .3 \\
\hline New York Heart Association class $\geq$ III & $197(95 \%)$ & $38(97 \%)$ & $21(95 \%)$ & .8 \\
\hline Body mass index $\left(\mathrm{kg} / \mathrm{m}^{2}\right)$ & $26 \pm 5$ & $27 \pm 6$ & $27 \pm 6$ & .6 \\
\hline Serum creatinine $(\mathrm{mg} / \mathrm{dL})$ & $0.97 \pm 0.2$ & $0.99 \pm 0.2$ & $0.96 \pm 0.2$ & .9 \\
\hline
\end{tabular}

$M V$, Mitral valve; $P M R$, papillary muscle reorientation. 
TABLE 2. Baseline echocardiographic characteristics of the study population

\begin{tabular}{|c|c|c|c|c|}
\hline & Group 1 & Group 2 & Group 3 & $P$ value \\
\hline Maximal end-diastolic basal septal thickness $(\mathrm{cm})$ & $2.17 \pm 0.5$ & $2.01 \pm 0.4$ & $1.66 \pm 0.4$ & $<.001$ \\
\hline Maximal end-diastolic posterior wall thickness $(\mathrm{cm})$ & $1.38 \pm 0.3$ & $1.39 \pm 0.3$ & $1.23 \pm 0.2$ & .07 \\
\hline Left ventricular ejection fraction $(\%)$ & $63 \pm 5$ & $62 \pm 6$ & $61 \pm 5$ & .2 \\
\hline $\begin{array}{l}\text { Degree of resting mitral regurgitation, mean } \pm \mathrm{SD} \text {; } \\
\text { median (interquartile range) }\end{array}$ & $1.8 \pm 1.0 ; 2(1-3)$ & $1.9 \pm 1.3 ; 2(1-3)$ & $1.3 \pm 0.8 ; 1(0.5-2)$ & .07 \\
\hline $\begin{array}{l}\text { Baseline resting peak LVOT gradient }(\mathrm{mm} \mathrm{Hg}) \\
\text { mean } \pm \mathrm{SD} \text {; median (interquartile range) }\end{array}$ & $62 \pm 42 ; 58(24-98)$ & $65 \pm 47 ; 57(17-105)$ & $41 \pm 41 ; 33(11-64)$ & .08 \\
\hline $\begin{array}{l}\text { Baseline maximal (either resting or provocable) } \\
\text { peak LVOT gradient (mm } \mathrm{Hg} \text { ), } \\
\text { mean } \pm \mathrm{SD} \text {; median (interquartile range) }\end{array}$ & $103 \pm 32 ; 100(85-119)$ & $103 \pm 32 ; 100(81-120)$ & $114 \pm 36 ; 116(87-133)$ & .3 \\
\hline
\end{tabular}

have been 2 deaths in the study population. The first death occurred in a 71-year-old woman in group 1 (postoperative day 48), and the cause of death is unknown. The second death occurred in a 52-year-old woman in group 2 and was caused by a pulmonary embolism (postoperative day 47). There have been no deaths in group 3.

In addition, we made follow-up telephone calls to all patients in group 3. At a mean follow-up of 224 days (median, 166 days; interquartile range, 74-343 days), 21 of 22 patients were in functional class I with no functional limitation and were free from reoperation. Only 1 patient in group 3 who underwent papillary muscle reorientation only (a 53year-old man; preoperative basal septal thickness, $1.5 \mathrm{~cm}$; maximal baseline LVOT gradient, $132 \mathrm{~mm} \mathrm{Hg}$ ) had a recurrent provocable LVOT gradient at the 3-month follow-up $(87 \mathrm{~mm} \mathrm{Hg})$, in addition to moderately severe mitral regurgitation, SAM, and progression to NYHA class III symptoms. This patient subsequently underwent mitral valve replacement and is currently symptom free and alive.
From group 3, 11 other patients have returned for followup clinic visits and echocardiograms. The average resting and maximal LVOT gradients were $9 \pm 8$ and $10 \pm 10$ $\mathrm{mm} \mathrm{Hg}$, respectively. All these patients had trivial mitral regurgitation and no evidence of SAM.

\section{DISCUSSION}

This study is the first to report characteristics and shortterm outcomes in a series of patients with HCM with symptomatic dynamic LVOT obstruction despite maximal medical therapy who underwent papillary muscle reorientation with or without myectomy. The baseline characteristics were similar (except for lesser frequency of atrial fibrillation) to those of the typical symptomatic population of patients with HCM who underwent myectomy with or without mitral valve surgery. Although the degree of provocable LVOT gradient was similar, the patients in group $3 \mathrm{had}$ a significantly thinner basal septum; in fact, there were 11 patients with a basal septal thickness of less than $1.5 \mathrm{~cm}$.

TABLE 3. Perioperative and postoperative characteristics of the study population

\begin{tabular}{|c|c|c|c|c|}
\hline & Group 1 & Group 2 & Group 3 & $P$ value \\
\hline Concomitant coronary artery bypass surgery & $22(15 \%)$ & $2(5 \%)$ & $1(5 \%)$ & .1 \\
\hline Admission days during operation & $8 \pm 5$ & $8 \pm 6$ & $6 \pm 2$ & .3 \\
\hline Intensive care unit days & $1.6 \pm 1.3$ & $1.6 \pm 1.4$ & $1.6 \pm 1$ & .9 \\
\hline Myocardial infarction & 0 & 0 & 0 & \\
\hline Bleeding & $4(3 \%)$ & 0 & $1(5 \%)$ & .3 \\
\hline Stroke & 0 & 0 & 0 & \\
\hline Renal failure & 0 & 0 & 0 & \\
\hline New permanent pacemaker & $13(9 \%)$ & $3(8 \%)$ & 0 & .1 \\
\hline New left bundle branch block & $143(100 \%)$ & $39(100 \%)$ & $16(73 \%)$ & $<.01$ \\
\hline $\begin{array}{l}\text { Resting peak LVOT gradient }(\mathrm{mm} \mathrm{Hg}) \text {, mean } \pm \mathrm{SD} \text {; } \\
\text { median (interquartile range) }\end{array}$ & $10 \pm 10 ; 10(0-16)$ & $9 \pm 9 ; 8(0-18)$ & $9 \pm 9 ; 9(0-16)$ & .8 \\
\hline $\begin{array}{l}\text { Maximal (Valsalva or amyl nitrite) peak LVOT } \\
\text { gradient }(\mathrm{mm} \mathrm{Hg}) \text {, mean } \pm \mathrm{SD} \text {; median } \\
\text { (interquartile range) }\end{array}$ & $15 \pm 18 ; 12(0-22)$ & $14 \pm 14 ; 14(0-26)$ & $16 \pm 21 ; 11(0-18)$ & .9 \\
\hline $\begin{array}{l}\text { Postoperative mitral regurgitation, mean } \pm \mathrm{SD} \text {; } \\
\text { median (interquartile range) }\end{array}$ & $0.5 \pm 0.5 ; 0.5(0.5-0.5)$ & $0.5 \pm 0.4 ; 0.5(0.5-0.5)$ & $0.4 \pm 0.3 ; 0.5(0.5-0.5)$ & .3 \\
\hline Reoperation during follow-up & 0 & 0 & 1 & \\
\hline 30-d Mortality & 0 & 0 & 0 & \\
\hline
\end{tabular}

The groups are those described in Table 1. $S D$, Standard deviation; $L V O T$, left ventricular outflow tract. 
We report a high procedural success rate with this novel technique, with no in-hospital or 30-day mortality and a similar rate of perioperative complications compared with standard techniques. On predischarge echocardiographic analysis, all patients had successful relief of resting and provocable LVOT obstruction. Furthermore, there was significant reduction of the degree of mitral regurgitation to a similar extent in all groups. No patient in the papillary muscle reorientation group required a permanent pacemaker in the postoperative setting.

At short-term follow-up, all patients in group 3 (except for 1 patient) were asymptomatic and without a need for reoperation. Only 1 patient presented with persistent symptoms and increased LVOT gradient after undergoing papillary muscle reorientation during follow-up. This patient was one of the initial patients who underwent isolated papillary muscle reorientation and was symptom free at discharge. However, he presented with a sudden worsening shortness of breath 2 months after his operation and was found to have an increased LVOT gradient and SAM, requiring surgical reintervention. Intraoperatively, the sutures on the posterior aspect of the bifid anterolateral muscle had dislodged, resulting in resumption of the laxity in the anterolateral papillary muscle. Although we could have replaced the suture, it was a clinical decision not to do so because the patient was relatively young and we did not want to subject him to another operation should simple resuturing have failed again. This patient subsequently underwent mitral valve replacement and recovered normally, is currently alive, and is asymptomatic. We do not report the short- and long-term outcomes data of groups 1 to 3 because they have been previously published. ${ }^{8,13}$

Dynamic LVOT obstruction is responsible for a sizable proportion of symptoms associated with HCM. An increased LVOT gradient carries prognostic significance in patients with $\mathrm{HCM},{ }^{23}$ and such patients with a resting gradient of $30 \mathrm{~mm} \mathrm{Hg}$ or greater had a 4-fold increased risk of death or progression to severe congestive symptoms compared with those without obstruction. ${ }^{3}$ Furthermore, the resolution of LVOT gradient has been demonstrated to improve survival. ${ }^{3,6}$ An increase in the size of the LVOT is traditionally achieved through surgical myectomy (with or without mitral valve surgery) or alcohol septal ablation, with excellent outcomes. ${ }^{4-8}$

However, recent studies with high-resolution 3-dimensional CMR have demonstrated a high frequency of papillary muscle abnormalities (anteroapical displacement, double bifid papillary muscles, or both) in patients with $\mathrm{HCM}$, which are frequently missed on echocardiographic analysis. ${ }^{10,16}$ In the study by Kwon and colleagues, ${ }^{10}$ the odds of having an abnormal resting LVOT gradient were significantly higher in those patients with HCM who also had abnormal papillary muscles, independent of septal thickness.
Previous studies have also demonstrated the effect of altered papillary muscle morphology in dogs. This study reproduced SAM in dogs with structurally normal hearts and mitral valves by anteriorly displacing the papillary muscles through a suture mechanism. ${ }^{24}$ SAM in these dogs was a result of the decrease in effective posterior restraint (increased leaflet slack) caused by anterior redirection of papillary muscle tension, increased length of the residual leaflet, and coaptation of the mitral valve leaflets in LVOT, subjecting the leaflets to drag forces ${ }^{25}$ that propel the leaflet anteriorly. The anteriorly displaced leaflets are more likely pushed into the LVOT by drag forces, as opposed to the Venturi effect, because the onset of SAM occurs when the velocity in the LVOT is normal or low.

\section{Clinical Implications}

In our clinical practice we have seen multiple patients with dynamic LVOT obstruction in the setting of minimal or no basal septal hypertrophy. It is not clear whether this represents an earlier stage of the HCM disease process before the development of characteristic basal septal hypertrophy. In a recent case report, we described a highly symptomatic 18-year-old patient with normal septal thickness and a significant LVOT gradient. This patient was noted to have multiple hypermobile papillary muscles heads that obstructed the LVOT during systole. This patient was gene positive for HCM. The LVOT obstruction was effectively eliminated by means of papillary muscle reorientation alone without myectomy. ${ }^{15}$ As one might recognize, this subgroup of patients with HCM presents a surgical dilemma if medical therapy fails because the basal septum is not "thick enough" to contribute to LVOT obstruction. Therefore performing extensive myectomy in such patients would only put them at risk for iatrogenic ventricular septal defect without effectively alleviating of the obstruction. Performing mitral valve repair (including an Alfieri stitch) would also not be appropriate in such patients. Similarly, performing alcohol septal ablation would also not be of any clinical utility.

In our experience reorientation of 1 or more papillary muscle heads away from the LVOT effectively and safely relieves obstruction while concomitantly preserving mitral valve function. Also, because in most cases this can be achieved by no myectomy (or at most a minimyectomy of $<5 \mathrm{~mm}$ ), potential injury to the conduction system and pacemaker dependence could also be less of a concern. However, this needs to be validated with longer-term follow-up.

Thus at our institution, we use the following pathway for management of patients with dynamic LVOT obstructions and intractable symptoms. The first step is to establish the morphologic basis of dynamic LVOT obstruction with multimodality imaging: basal septal hypertrophy versus mitral pathology versus papillary muscle hypermobility. The vast majority of patients with dynamic LVOT obstruction have 
basal septal hypertrophy and SAM. This group requires an extensive myectomy. A smaller proportion of patients with dynamic LVOT obstruction have concomitant mitral valve pathology that needs to be addressed at the time of myectomy to yield optimal results. There is another small group of patients who have an obvious symptomatic dynamic LVOT obstruction without significant basal septal hypertrophy. These patients need to be further evaluated for 2 scenarios, isolated intrinsic mitral valve pathology or bifid/apically displaced papillary muscle that is hypermobile. In the first scenario mitral valve repair/replacement is the optimal approach, and in the second scenario (hitherto underrecognized) we approach it using papillary muscle reorientation. Of course, there have been a few patients in whom we have performed all 3 procedures for optimal relief of obstruction.

\section{Limitations and Future Outlook}

We acknowledge the following limitations of our study. The study was conducted at a tertiary referral center with a significant selection bias. The patients in our study had significant symptoms and were therefore referred to our center for a cardiac evaluation. Assessment of papillary muscle morphology by means of multimodality imaging is not standardized, and at present, it is subjective based on visual assessment. One might argue that the papillary muscle reorientation (in addition to myectomy) might not have been necessary, particularly in patients of group 3, who already had a relatively thick basal septum. However, a decision regarding the choice of operative approach in this group was made based on expert consensus after detailed multimodality imaging evaluation and an understanding that myectomy alone would be insufficient, whereas mitral valve surgery would remain unindicated. Certainly, extensive myectomy was not an option in group 3 patients with the basal septum measured at less than $1.5 \mathrm{~cm}$.

Dedicated multimodality imaging protocols that objectively detail papillary muscle morphology (especially with CMR) need to be established and validated prospectively. In the current study CMR was not uniformly performed in all patients because of various contraindications (most common being a pacemaker/defibrillator), as outlined before. Also, although papillary muscle reorientation is a relatively simple surgical technique, expertise after an obligatory learning curve would need to be developed. Finally, longer-term follow-up is needed to compare outcomes (including freedom from reoperation) for papillary muscle reorientation with or without surgical myectomy vs myectomy alone in a more comprehensive manner.

\section{CONCLUSIONS}

In a subset of patients with HCM who have bifid, hypermobile papillary muscles (with or without basal interventricular septal hypertrophy), papillary muscle reorientation effectively reduces LVOT obstruction, without a need for mitral valve replacement. Although short-term outcomes (including freedom from reoperation) are good, long-term outcomes need to be ascertained.

\section{References}

1. Martin RP, Rakowski H, French J, Popp RL. Idiopathic hypertrophic subaortic stenosis viewed by wide-angle, phased-array echocardiography. Circulation. 1979;59:1206-17.

2. Pollick C, Rakowski H, Wigle ED. Muscular subaortic stenosis: the quantitative relationship between systolic anterior motion and the pressure gradient. Circulation. 1984;69:43-9.

3. Maron MS, Olivotto I, Betocchi S, Casey SA, Lesser JR, Losi MA, et al. Effect of left ventricular outflow tract obstruction on clinical outcome in hypertrophic cardiomyopathy. N Engl J Med. 2003;348:295-303.

4. Kwon DH, Kapadia SR, Tuzcu EM, Halley CM, Gorodeski EZ, Curtin RJ, et al. Long-term outcomes in high risk symptomatic patients with hypertrophic cardiomyopathy undergoing alcohol septal ablation. JACC Cardiovasc Interv. 2008; 432-8.

5. Sorajja P, Valeti U, Nishimura RA, Ommen SR, Rihal CS, Gersh BJ, et al. Outcome of alcohol septal ablation for obstructive hypertrophic cardiomyopathy. Cir culation. 2008;118:131-9.

6. Ommen SR, Maron BJ, Olivotto I, Maron MS, Cecchi F, Betocchi S, et al. Longterm effects of surgical septal myectomy on survival in patients with obstructive hypertrophic cardiomyopathy. J Am Coll Cardiol. 2005;46:470-6.

7. Heric B, Lytle BW, Miller DP, Rosenkranz ER, Lever HM, Cosgrove DM. Surgical management of hypertrophic obstructive cardiomyopathy. Early and late results. J Thorac Cardiovasc Surg. 1995;110:195-208.

8. Smedira NG, Lytle BW, Lever HM, Rajeswaran J, Krishnaswamy G, Kaple RK, et al. Current effectiveness and risks of isolated septal myectomy for hypertrophic obstructive cardiomyopathy. Ann Thorac Surg. 2008;85:127-33.

9. Klues HG, Roberts WC, Maron BJ. Anomalous insertion of papillary muscle directly into anterior mitral leaflet in hypertrophic cardiomyopathy. Significance in producing left ventricular outflow obstruction. Circulation. 1991;84 1188-97.

10. Kwon DH, Setser RM, Thamilarasan M, Popovic ZV, Smedira NG Schoenhagen $\mathrm{P}$, et al. Abnormal papillary muscle morphology is independently associated with increased left ventricular outflow tract obstruction in hypertrophic cardiomyopathy. Heart. 2008;94:1295-301.

11. Klues HG, Maron BJ, Dollar AL, Roberts WC. Diversity of structural mitral valve alterations in hypertrophic cardiomyopathy. Circulation. 1992;85:1651-60.

12. Klues HG, Roberts WC, Maron BJ. Morphological determinants of echocardiographic patterns of mitral valve systolic anterior motion in obstructive hypertrophic cardiomyopathy. Circulation. 1993;87:1570-9.

13. Kaple RK, Murphy RT, DiPaola LM, Houghtaling PL, Lever HM, Lytle BW, et al. Mitral valve abnormalities in hypertrophic cardiomyopathy: echocardiographic features and surgical outcomes. Ann Thorac Surg. 2008;85:1527-35. e1-2.

14. Maron BJ, Epstein SE, Bonow RO, Wyngaarden MK, Wesley YE. Obstructive hypertrophic cardiomyopathy associated with minimal left ventricular hypertrophy. Am J Cardiol. 1984;53:377-9.

15. Austin BA, Kwon DH, Smedira NG, Thamilarasan M, Lever HM, Desai MY. Abnormally thickened papillary muscle resulting in dynamic left ventricular outflow tract obstruction: an unusual presentation of hypertrophic cardiomyopathy. $J \mathrm{Am}$ Soc Echocardiogr. 2009;22(105):e5-6.

16. Harrigan CJ, Appelbaum E, Maron BJ, Buros JL, Gibson CM, Lesser JR, et al. Significance of papillary muscle abnormalities identified by cardiovascular magnetic resonance in hypertrophic cardiomyopathy. Am J Cardiol. 2008;101: 668-73.

17. Bryant R 3rd, Smedira NG. Papillary muscle realignment for symptomatic lef ventricular outflow tract obstruction. J Thorac Cardiovasc Surg. 2008;135:223-4.

18. Gottdiener JS, Bednarz J, Devereux R, Gardin J, Klein A, Manning WJ, et al. American Society of Echocardiography recommendations for use of echocardiography in clinical trials. J Am Soc Echocardiogr. 2004;17:1086-119.

19. Nakatani S, Marwick TH, Lever HM, Thomas JD. Resting echocardiographic features of latent left ventricular outflow obstruction in hypertrophic cardiomyopathy. Am J Cardiol. 1996;78:662-7.

20. Drinko JK, Nash PJ, Lever HM, Asher CR. Safety of stress testing in patients with hypertrophic cardiomyopathy. Am J Cardiol. 2004;93:1443-4, A12. 
21. Shiota T, Jones M, Teien D, Yamada I, Passafini A, Knudson O, et al. Color Doppler regurgitant jet area for evaluating eccentric mitral regurgitation: an animal study with quantified mitral regurgitation. J Am Coll Cardiol. 1994;24: 813-9.

22. Marwick TH, Stewart WJ, Lever HM, Lytle BW, Rosenkranz ER, Duffy CI, et al. Benefits of intraoperative echocardiography in the surgical management of hypertrophic cardiomyopathy. J Am Coll Cardiol. 1992;20:1066-72.

23. Autore C, Bernabo P, Barilla CS, Bruzzi P, Spirito P. The prognostic importance of left ventricular outflow obstruction in hypertrophic cardiomyopathy varies in relation to the severity of symptoms. J Am Coll Cardiol. 2005;45: 1076-80.

24. Levine RA, Vlahakes GJ, Lefebvre X, Guerrero JL, Cape EG, Yoganathan AP, et al. Papillary muscle displacement causes systolic anterior motion of the mitral valve. Experimental validation and insights into the mechanism of subaortic obstruction. Circulation. 1995;91:1189-95.

25. Sherrid MV, Chu CK, Delia E, Mogtader A, Dwyer EM Jr. An echocardiographic study of the fluid mechanics of obstruction in hypertrophic cardiomyopathy. J Am Coll Cardiol. 1993;22:816-25.

Access to The Journal of Thoracic and Cardiovascular Surgery Online is reserved for print subscribers!

Full-text access to The Journal of Thoracic and Cardiovascular Surgery Online is available for all print subscribers. To activate your individual online subscription, please visit The Journal of Thoracic and Cardiovascular Surgery Online, point your browser to http://www.mosby.com/jtcvs, follow the prompts to activate your online access, and follow the instructions. To activate your account, you will need your subscriber account number, which you can find on your mailing label (note: the number of digits in your subscriber account number varies from 6 to 10). See the example below in which the subscriber account number has been circled:

\section{Sample mailing label}

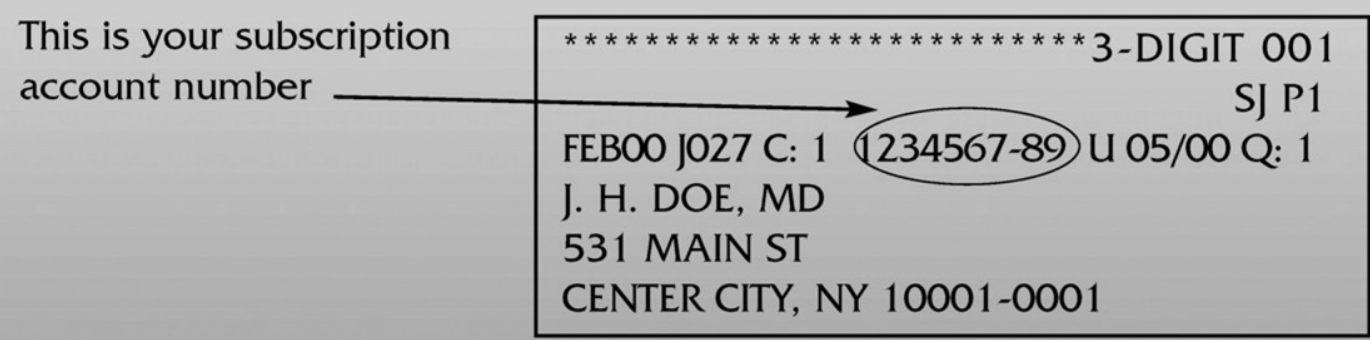

Personal subscriptions to The Journal of Thoracic and Cardiovascular Surgery Online are for individual use only and may not be transferred. Use of The Journal of Thoracic and Cardiovascular Surgery Online is subject to agreement to the terms and conditions as indicated online. 